http://jmscr.igmpublication.org/home/

ISSN (e)-2347-176x ISSN (p) 2455-0450

crossref DOI: https://dx.doi.org/10.18535/jmscr/v7i7.42

Journal Of Medical Science And Clinical Research

\title{
Ventilator-Associated Pneumonia: The Effect of Bacterial Resistance
}

\author{
Authors \\ Yousry Elsaeed Risk ${ }^{1}$, Mohamed Abd Elmohsen Elmahdy ${ }^{2}$, Ahmed Hamdy Abd \\ Elrahman $^{3}$, Bassem Mefreh Aglan ${ }^{4}$, Mohamed Ossama Mohamed Abd Elsadek ${ }^{5}$ \\ ${ }^{1}$ Professor of Critical CareFaculty of Medicine Benha University \\ ${ }^{2}$ Assist. Prof. of Chest Disease Faculty of Medicine Benha University \\ ${ }^{3}$ Lecturer of Anesthesia and Intensive Care Faculty of Medicine Benha University \\ ${ }^{4}$ Lecturer of Cardiothoracic Surgery Faculty of Medicine Benha University \\ ${ }^{5}$ Resident of Critical Care Faculty of Medicine Benha University
}

\begin{abstract}
Background: there have been many study in preventing ventilator-associated pneumonia (VAP), Although it $V A P$ remains the most diffuse Hospital aquired infection in intensive care units $(I C U)^{(1)}$. VAP worse patient recovery and increasing length of hospitalization, duration of mechanical ventilation, and hospitalization costs. ${ }^{(2)}$

Moreover, VAP is lead to increase mortality rates (14-70\%), due to resistant bacteria, inappropriate antimicrobial therapy use, and incorrect antimicrobial prescription or de-escalation therapy. ${ }^{(3,4)}$

Patients and Methods: This study was done on 40 patients in ICU at Benha University Hospital in the period from august 2017 to march 2019. who were put on mechanical ventilation and diagnosed to have VAP.19 patients died in our study and 21 patients were discharged alive.

Results: This study observed that error in maintenance dose treatment, error in treatment duration and delay in starting antimicrobial therapy followed by the interval between doses, error in loading dose and inappropriate adjustment for renal function. were found increased in patients who died. de-escalation therapy compared to maintenance therapy lead to low mortality rates and higher mortality rates in older patients with more comorbidities..

Keywords: ventilator-associated pneumonia; mechanical ventilation; antimicrobial prescription.
\end{abstract}

\section{Introduction}

Many risk factors have been demonstrated to be associated with VAP. generaly, these factors can be divided into several broad categories: intrinsic host factors such as age, underlying medical disorders such as pulmonary disease, and nutritional status, hospital factors such as abdominal or thoracic operations, antibiotic use, immunosuppression, and treatment in an ICU, equipment and device use, especially intubation with mechanical ventilation and increase the risk of aspiration by many factos such as depressed consciousness.

VAP is often caused by multidrug resistant organisms, which may decrease therapeutic options and lead to bad prognosis. ${ }^{(5)}$

becouse of VAP is associated with significant morbidity and mortality, the proper choice of 
initial empiric treatment wil associated with significant decrease in rate of morbidity and mortality in infection with VAP.and perform aproper prescription of antimicrobial therapy should also consider as the type, dosage, and duration of drug administration.

Although many triales for study of VAP prophylaxis and treatment are available, therapy still varies significantly between institutions and the pressence of incorrect prescription is quite high, ranging from $10 \%$ to $73 \%$. $^{(6)}$

\section{Patients and Methods}

This study was done on 40 patients who were admitted to the adult ICU of Benha University Hospital. Patients presented in our study were diagnosed to have VAP. Diagnosis was established on many criteria decided by the American Thoracic Society and the Infectious Diseases Society of America (7) including mechanical ventilation for at least $48 \mathrm{~h}$ and appearance of new or progressive pulmonary infiltrate on chest radiographs associated with at least two clinical signs and/or laboratory changes suggesting an ongoing infection, including fever $\left(>38{ }^{\circ} \mathrm{C}\right)$ or hypothermia $\left(<35^{\circ} \mathrm{C}\right)$; leukocytosis $(>10,000 / \mathrm{mm} 3)$ or leukopenia $(<4000 / \mathrm{mm} 3)$; purulent tracheal secretions and oxygenation changes.

Data on drug prescription of antimicrobial therapy were obtained, including whether treatment was given after obtaining the results of sensitivity profiling using quantitative culture, as:

1. De-escalation (Discontinuation of antimicrobial therapy or replacement with antimicrobials with limited spectrum coverage).

2. Escalation (Add new antimicrobial or replace with broad-spectrum antimicrobial).

3. Maintenance (Preserve the antimicrobial described initially or replace the antimicrobial with the same cover profile).

Errors in antimicrobial prescription were classified as follows: inappropriate choice:
1- Inappropriate adjustment for body weight (the dose not corrected according to patient weight).

2- The dose not adjusted according to renal function.

3- Errors in treatment duration (prescription for shorter or longer duration than period indicated).

To analyze the adequacy of treatment based on literature, we used guidance recommendations for management and health care for adults with pneumonia associated with mechanical ventilation from the American Thoracic Society and theDiseases Society of America ${ }^{(7)}$ TheSanford Guide to Antimicrobial Therapy ${ }^{(7)}$ were used as criteria for decisions about starting time:

1. Dose adjustments when necessary for weight and renal function. ${ }^{(8)}$

2. Error in starting of antibiotic therapy was defined by the Surviving Sepsis Campaign $^{(9)}$ as more than one hour between prescription of the first antibiotic dose and administration of it to the patient.

\section{Results}

This study was done on patients and subjects in ICU at Banha University Hospital.in the period from august 2018 to march 2019.Out of 100 patients were mechanically ventilated, 40 patients developed episode of VAP. in this study 19 patients died and 21 patients were discharged alive.

\begin{tabular}{|l|c|c|}
\hline Mortality & N & \% \\
\hline Discharge & 21 & 52.5 \\
\hline Died & 19 & 47.5 \\
\hline Total & 40 & 100 \\
\hline
\end{tabular}

Age in the studied groups were $22.5 \%$ less than 60 years with mortality $0 \%$ and $77.5 \%$ more than 60 years with higher mortality $100(p=0.001)$, sex in the studied groups were $45 \%$ male with mortality $26.3 \%$ and $55 \%$ female with higher mortality $73.7 \%$ ( $p=0.024)$, Days of hospitalization in the studied groups were $45 \%$ less than 21days with mortality $47.4 \%$ and $55 \%$ more than 21 days with 
higher mortality 52.6\% $(p=0.775)$, admission APACHE II prognostic index scores of $18.05 \pm$ 2.11 in Discharge and $24.47 \pm 3.03$ in died and, admission APACHE II prognostic index scores of $38.81 \pm 4.51 \mathrm{in}$ Discharge and $57.68 \pm 11.48$ in died with $(p=0.001)$, Neurologic cases in the studied groups were $65 \%$ with mortality $73.7 \%$ and $57.1 \%$ discharge $(p=0.273)$, trauma cases in the studied groups were $10 \%$ with mortality $0 \%$ and $19.0 \%$ discharge $(p=0.045)$, Respiratory casesin the studied groups were $25 \%$ with mortality $26.3 \%$ and $23.8 \%$ discharge ( $p=0.855)$, Infectious cases in the studied groups were $32.5 \%$ with mortality $47.4 \%$ and $19 \%$ discharge $(p=$ 0.056), Cardiovascular cases in the studied groups were $45 \%$ with mortality $47.4 \%$ and $42.9 \%$ discharge $(p=0.775)$, Others cases(Burned and pancreatitis). in the studied groups were $10 \%$ with mortality $5.3 \%$ and $14.3 \%$ discharge $(p=0.342)$, Smoking in the studied groups were $25 \%$ with mortality $26.3 \%$ and $23.8 \%$ discharge $(p=$ $0.855)$,systemic arterial hypertension cases in the studied groups were $90 \%$ with mortality $89 \%$ and $90.5 \%$ discharge $(p=0.916)$, Alcoholism in the studied groups were $0 \%$ with mortality $0 \%$ and $0 \%$ discharge, DM patient in the studied groups were $80 \%$ with mortality $100 \%$ and $61.9 \%$ discharge $(p$ $=0.003)$, Heart disease patient in the studied groups were $57.5 \%$ with mortality $73.7 \%$ and $42.9 \%$ discharge ( $p=0.049$ ), Lung disease patient in the studied groups were $75 \%$ with mortality $73.7 \%$ and $76.2 \%$ discharge $(p=0.855)$.

Table (1): Distribution of Prescription errors among the surveyed ICU patients

\begin{tabular}{|l|c|c|c|c|c|c|}
\hline \multirow{2}{*}{ Prescription errors } & \multicolumn{2}{c|}{$\begin{array}{c}\text { Discharge } \\
\mathbf{( N = 2 1 )}\end{array}$} & \multicolumn{2}{c|}{$\begin{array}{c}\text { Died } \\
(\mathbf{N = 1 9 )}\end{array}$} & \multirow{2}{*}{$\mathbf{X}^{\mathbf{2}}$} & \multirow{2}{*}{ P-value } \\
\cline { 2 - 7 } & $\mathbf{N}$ & $\mathbf{\%}$ & $\mathbf{N}$ & $\mathbf{\%}$ & & \\
\hline Error in loading dose & 5 & 23.8 & 0 & 0 & 5.170 & $0.023^{*}$ \\
\hline Error in maintenance dose & 0 & 0 & 19 & 100 & 40.001 & $0.001^{*}$ \\
\hline Error in the interval between doses & 4 & 19 & 9 & 47.4 & 3.647 & 0.056 \\
\hline Delay in starting antimicrobial therapy & 0 & 0 & 10 & 52.6 & 14.737 & $0.001^{*}$ \\
\hline Inappropriate adjustment for renal function & 3 & 14.3 & 1 & 5.3 & 0.902 & 0.342 \\
\hline Error in treatment duration & 0 & 0 & 19 & 100 & 40.001 & $0.001^{*}$ \\
\hline
\end{tabular}

This table shows that mean Prescription errors in the studied groups were

The most common error in antimicrobial prescriptions was Error in maintenance dose treatment, Error in treatment duration and the interval between doses followed by Delay in starting antimicrobial therapy, Error in loading dose and Inappropriate adjustment for renal function. Analysis of the influence of prescription errors on mortality rate revealed increase in mortality in patients who received an Error in maintenance dose $(p=0.001)$, Error in treatment duration (0.001), Delay in starting antimicrobial therapy $(p=0.001)$, when the dosage was not adjusted for renal function $(p=0.432)$, Error in loading $\operatorname{dose}(p=0.023)$ and Error in the interval between doses $(p=0.056)$.

Table (2): Distribution of Conduct among the surveyed ICU patients

\begin{tabular}{|l|c|c|c|c|c|c|}
\hline \multirow{2}{*}{ Conduct } & \multicolumn{2}{|c|}{ Discharge (N=21) } & \multicolumn{2}{|c|}{ Died (N=19) } & \multirow{2}{*}{$\mathbf{X}^{\mathbf{2}}$} & \multirow{2}{*}{ P-value } \\
\cline { 2 - 5 } & $\mathbf{N}$ & $\mathbf{\%}$ & $\mathbf{N}$ & $\mathbf{\%}$ & & \\
\hline De-escalation & 8 & 38.1 & 0 & 0 & 9.048 & $0.003^{*}$ \\
\hline Escalation & 8 & 38.1 & 14 & 73.3 & 5.105 & $0.024^{*}$ \\
\hline Maintenance & 5 & 23.8 & 5 & 26.3 & 0.033 & 0.855 \\
\hline
\end{tabular}

This table shows that mean Conduct in the studied groups.

Initial antimicrobial therapy was De-escalation in $38.1 \%$ of Discharged cases and $0 \%$ of died cases with ( $\mathrm{p}=0.003)$, escalation in $38.1 \%$ of Discharged cases and $73.3 \%$ of died cases with (p $=0.024)$, and Maintained in $23.8 \%$ of Discharged cases and $26.3 \%$ of died cases with $(p=0.0 .033)$ 
Table (3): Distribution of Bacteria among the surveyed ICU patients

\begin{tabular}{|l|c|c|c|c|c|c|}
\hline \multirow{2}{*}{ Bacteria } & \multicolumn{2}{|c|}{$\begin{array}{c}\text { Discharge } \\
\text { (N=21) }\end{array}$} & \multicolumn{2}{c|}{$\begin{array}{c}\text { Died } \\
\text { (N=19) }\end{array}$} & \multirow{2}{*}{$\mathbf{X}^{\mathbf{2}}$} & \multirow{2}{*}{ P-value } \\
\cline { 2 - 7 } & $\mathbf{N}$ & $\mathbf{\%}$ & $\mathbf{N}$ & $\mathbf{\%}$ & & \\
\hline Pseudomonas aeruginosa Mr & 0 & 0 & 10 & 52.6 & 14.737 & $0.001^{*}$ \\
\hline Acinetobacter baumannii MR & 2 & 9.5 & 2 & 10.5 & 0.011 & 0.916 \\
\hline Staphylococcus aureus MR & 0 & 0 & 9 & 47.4 & 12.835 & $0.001^{*}$ \\
\hline Serratia & 0 & 0 & 0 & 0 & - & - \\
\hline Stenotrophomonasmaltophilia & 0 & 0 & 0 & 0 & - & - \\
\hline Klebsiella pneumoniaespp & 5 & 23.8 & 0 & 0 & 5.170 & $0.023^{*}$ \\
\hline Enterobacter spp & 0 & 0 & 0 & 0 & - & - \\
\hline Escherichia coli & 4 & 19 & 5 & 26.3 & 0.302 & 0.583 \\
\hline Staphylococcus epidermidis & 8 & 38.1 & 0 & 0 & 9.048 & $0.003^{*}$ \\
\hline
\end{tabular}

This table shows that mean Bacteria in the studied groups.

Infections which were caused by Pseudomonas aeruginosa in $0 \%$ of Discharge cases and $52.6 \%$ of died case $(\mathrm{p}=0.001)$, A. baumannii in $9.5 \%$ of Discharge cases and $10.5 \%$ of died case $(\mathrm{p}=$ $0.916)$, S. aureus in $0 \%$ of Discharge cases and $47.4 \%$ of died case( $\mathrm{p}=0.001)$, Klebsiella pneumoniae in $23.8 \%$ of Discharge cases and $0 \%$ of died case( $\mathrm{p}=0.023)$, Staphylococcus epidermidis, in $38.1 \%$ of Discharge cases and $0 \%$ of died case $(\mathrm{p}=0.003)$ and Escherichia coli in $19 \%$ of Discharge cases and $26.3 \%$ of died case (p $=0.583)$.

\section{Conclusions}

Conclusion, this study observed that Error in maintenance dose treatment, Error in treatment duration and Delay in starting antimicrobial therapy. were more frequent in patients who died. de-escalation therapy compared to maintenance therapy lead to low mortality rates. The higher mortality rates in older patients with more comorbidities.

\section{Financial support and sponsorship: Nil.}

Conflicts of interest: There are no conflicts of interest.

\section{Reference}

1. Rocha Lde A, Vilela CA, Cezário RC, Almeida AB,. Ventilator-associated pneumonia in an adult clinical-surgical intensive care unit of Brazilian university hospital: incidence, risk factors, etiology, and antibiotic resistance. Braz J Infect Dis. 2018; 12:80-5.

2. Hayashi Y, Morisawa K, et al. Toward improved surveillance: the impact of ventilator associated complications on length of stay and antibiotic use in patients in intensive care units. Clin Infect Dis. 2013; 56: 471-7.

3. Teixeira PJZ, Hertz FTP, Cruz DB, MoreiraJS. Pneumonia associada à ventilac, ãomecânica: impactoda multir resistência bacterianana morbidade e mortalidade. $\mathrm{J} \mathrm{Br}$ as Pneumol. 2014; 30:540-8.

4. Rello J, Vidaur L, Sandiumenge A, et al. De-escalation therapy in ventilator associated pneumonia. Crit Care Med. 2004; 32:2183-90.

5. Chung DR, Song JH, et al. High prevalence of multidrug-resistant non fermenters in hospital-acquired pneumonia in Asia. Am J Respir Crit Care Med. 2011; 184:1409-17.

6. Kollef MH, Morrow LE, Niederman MS, et al. Clinical characteristics and treatment patterns among patients with ventilatorassociated pneumonia. Chest. 2006; 5:1210-8.7

7. American Thoracic Society/Infectious Diseases Society of America. Guidelines for the management of adults with hospital-acquired, ventilator -associated, and healthcare-associated pneumonia. Am 
J Respir Crit Care Med. 2005;171:388416.

8. Gilbert DN, Chambers HF, Eliopoulos GM, Michael SS. The Sanford guide to antimicrobial therapy. Sperryville: Copyright; 2014.10.

9. Dellinger RP, Levy MM, Rhodes A, et al. Surviving sepsis campaign: international guidelines for management of severe sepsis and septic shock: 2012. Crit Care Med. 2012; 41:582-637. 